\title{
Adaptability Study and Effect Evaluation of Work Damage Unplugging Technology
}

\author{
Shasha Liu ${ }^{1, *}$, Ping Fang ${ }^{2}$, Tiantian Zhang ${ }^{1}$, Yunqi Zhang ${ }^{3}$, Pengfei Lei ${ }^{1}$, Meng Liu ${ }^{1}$, Fang Shang ${ }^{1}$, Zhenfeng Wang ${ }^{1}$, Kejia Wang ${ }^{1}$, \\ Wenhua $\mathrm{Han}^{4}$ \\ ${ }^{1}$ Petroleum Production Engineering Research Institute of Huabei Oilfield Company, Renqiu, Hebei Province, 062552 \\ ${ }^{2}$ The Third Exploit Factory of Huabei Oilfield Company, Hejian, Hebei Province, 062450 \\ ${ }^{3}$ Hohai University, college of environment, Nanjing, Jiangsu Province, 210098 \\ ${ }^{4}$ The Forth Exploit Factory of Huabei Oilfield Company, Langfang, Hebei Province, 065000
}

\begin{abstract}
In the process of oilfield development, the reservoir can be polluted by well cleaning, pump inspection and other operations. And that will lead to a long recovery period of oil well production after operation, and even the production is difficult to recover. In recent years, unplugging transformation and other technologies have been researched and applied, and certain results have been achieved. However, there is a lack of systematic evaluation and analysis on the applicability, advantages and disadvantages of various technologies. For this reason, the application effect of the existing technology is systematically analyzed and evaluated in terms of the formula of unplugging agent, unplugging process, damage mechanism, oil-water well relationship, production layer and other aspects by means of combination of geology and engineering. The adaptability of this technology is obtained, and it is used as the principle of well selection for subsequent technical application to further improve the effect of measures.
\end{abstract}

\section{Research Background}

In the process of well cleaning and pump inspection in various oil production plants of HB oilfield, well fluid enters the formation and reservoir pollution occurs, especially in water sensitive and low pressure reservoirs, which results in the failure of the oil well to recover normal production after operation and affects the effect of measures [1-5]. In recent years, the research and application of single well anti-swelling blockage remodeling techniques have been carried out, and some results have been obtained. However, there is a lack of systematic evaluation and analysis on the applicability, advantage and disadvantages of each technique.

Therefore, the application effect of the existing technology is systematically analyzed by combining engineering and geology, and the adaptability of the existing technology is finally determined. And this is used as well selection principle to further guide the technical application and improve the application effect.

\section{Methods and Procedures}

2.1 site construction process and technical requirements of workplace damage blocking technology

(1) The original water injection wellhead should be replaced with a 350 wellhead, or the original water injection wellhead should be installed with a highpressure wellhead extrusion device, and the four directions of the wellhead should be fixed with a tension rope and ground anchor.

(2) Well cleaning: Reverse circulation well cleaning until the water quality of casing inlet and outlet is consistent.

(3) Extrusion test: Pump truck is connected with the tubing valve to form the construction manifold, the casing valve is closed, the pressure test of the pipeline and the wellhead is $25 \mathrm{MPa}$, and it is qualified if the there is no puncture and no leakage.

(4) Test the produced water out, observe the pressure gauge reading, and determine the process control parameters.

(5) Extruding organic cleaning agent: The tank truck pulled $10 \mathrm{~m} 3$ of produced water, and poured the organic cleaning agent into the tank truck for dilution and reserve. The pump tank truck is connected to the tank truck, and the organic cleaning agent is being extruded. Pay attention to the pressure change during the extrusion process.

\footnotetext{
*Corresponding author: Liu Shasha, cyy_liuss@ @etrochina.com.cn.
} 
(6) Extruding unplugging agent: The pump truck is connected with the acid tank truck, and the designed amount of scale dissolving acid lotion is pressed into it. The pressure change is paid attention to during the extrusion process.

(7) Replace a certain amount of produced water.

(8) Shut in the well and let stand for 2-4 hours.

(9) Normal water injection in well opening.

\section{Application Effect Analysis and Discussion}

\subsection{Application effect analysis of typical block Q42}

The application of damage unplugging technology in Q42 fault block was systematically analyzed. Four wells were applied in the field, with a cumulative oil increase of $6636 \mathrm{t}$ in the stage, and the effective rate was $100 \%$. All the measures were effective and the input-output ratio was high. The total input-output ratio of the four wells was 1:38. Different unplugging measures with the same fault block have different effects. After unplugging operation, the Q42-78X well with the best effect was compared with that before the construction. The oil output was added $6.6 \mathrm{t}$ per day, which has been effective since the construction in September 2017, and the stage accumulated oil was 5235t. The less effective well Q42$9 \mathrm{X}$ added $1.6 \mathrm{t}$ of oil per day after the treatment, but the treatment had a short term, and the production dropped to $3.5 \mathrm{t} / \mathrm{d}$ five months after the treatment.

Table 1 Statistical table of the effect of blockage removal technology in the Q42 fault block against the operation injury

\begin{tabular}{|c|c|c|c|c|c|c|c|c|c|c|c|c|c|c|c|}
\hline \multirow{2}{*}{ No. } & \multirow{2}{*}{ Well no. } & \multirow{2}{*}{ Construction date } & \multicolumn{4}{|c|}{ Before carrying out } & \multicolumn{4}{|c|}{ After carrying out } & \multicolumn{2}{|c|}{ Contrast } & \multirow{2}{*}{$\begin{array}{c}\text { Cumulat } \\
\text { ive oil } \\
\text { increase, } \\
\mathbf{t}\end{array}$} & \multirow{2}{*}{$\begin{array}{l}\text { Input- } \\
\text { output ratio }\end{array}$} & \multirow[b]{2}{*}{ Note } \\
\hline & & & $\begin{array}{c}\text { Daily } \\
\text { liquid, } t / d\end{array}$ & $\begin{array}{c}\text { Daily oil, } \\
\mathbf{t} / \mathbf{d}\end{array}$ & $\begin{array}{c}\text { Moisture } \\
\text { content, } \\
\%\end{array}$ & $\begin{array}{c}\text { Working } \\
\text { fluid level } \\
\text { m }\end{array}$ & $\begin{array}{c}\text { Daily } \\
\text { liquid, } t / d\end{array}$ & $\begin{array}{c}\text { Daily oil, } \\
\mathbf{t} / \mathbf{d}\end{array}$ & $\begin{array}{c}\text { Moisture } \\
\text { content, } \\
\%\end{array}$ & $\begin{array}{c}\text { Working } \\
\text { fluid } \\
\text { level, } \mathbf{m}\end{array}$ & $\begin{array}{c}\text { Growing } \\
\text { liquid, } \\
\text { t/d }\end{array}$ & $\begin{array}{c}\text { Growing } \\
\text { oil, } t / d\end{array}$ & & & \\
\hline 1 & Q42-78X & 2017.9.22 & 3.1 & 3.1 & 0 & 1521 & 9.7 & 9.7 & 0 & 1370 & 6.6 & 6.6 & 5235 & $1: 120$ & \\
\hline 2 & Q42-74X & 2017.11.22 & 1.4 & 1.32 & 5.7 & 1450 & 2.5 & 2.5 & 0 & 1380 & 1.1 & 1.18 & 384 & $1: 8.9$ & \\
\hline 3 & Q42-52X & 2017.11.14 & 0.12 & 0 & 0 & 1365 & 1.2 & 1.2 & 0 & 1345 & 0.8 & 0.8 & 844 & $1: 20$ & \\
\hline 4 & Q42-9X & 2017.12.15 & 3.8 & 3.8 & 0 & 1490 & 5.4 & 5.4 & 0 & 1365 & 1.6 & 1.6 & 173 & $1: 4$ & $\begin{array}{l}\text { Production } \\
\text { fell to } 3.5 t / d \\
\text { five months } \\
\text { after the } \\
\text { measure }\end{array}$ \\
\hline
\end{tabular}

\subsubsection{With good connectivity between oil and water wells and good water flooding effect, the effect is more significant after unplugging}

Through the analysis of injection-production correspondence, it was found that well Q42-78X has a good material foundation, with a daily oil production of $6.1 \mathrm{t} / \mathrm{d}$ and a high production rate before unplugging. The wells had sufficient formation energy after blockage removal and maintain high production which had good connectivity with water injection wells and good water flooding effect. Well Q42-9X was effective for 5 months. The well had multiple perforated layers, large thickness, $16.8 \mathrm{~m} / 5$ layers, and poor permeability existed between layers. The unplugging agent selectively entered the reservoir, leading to poor unplugging effect in some layers. 


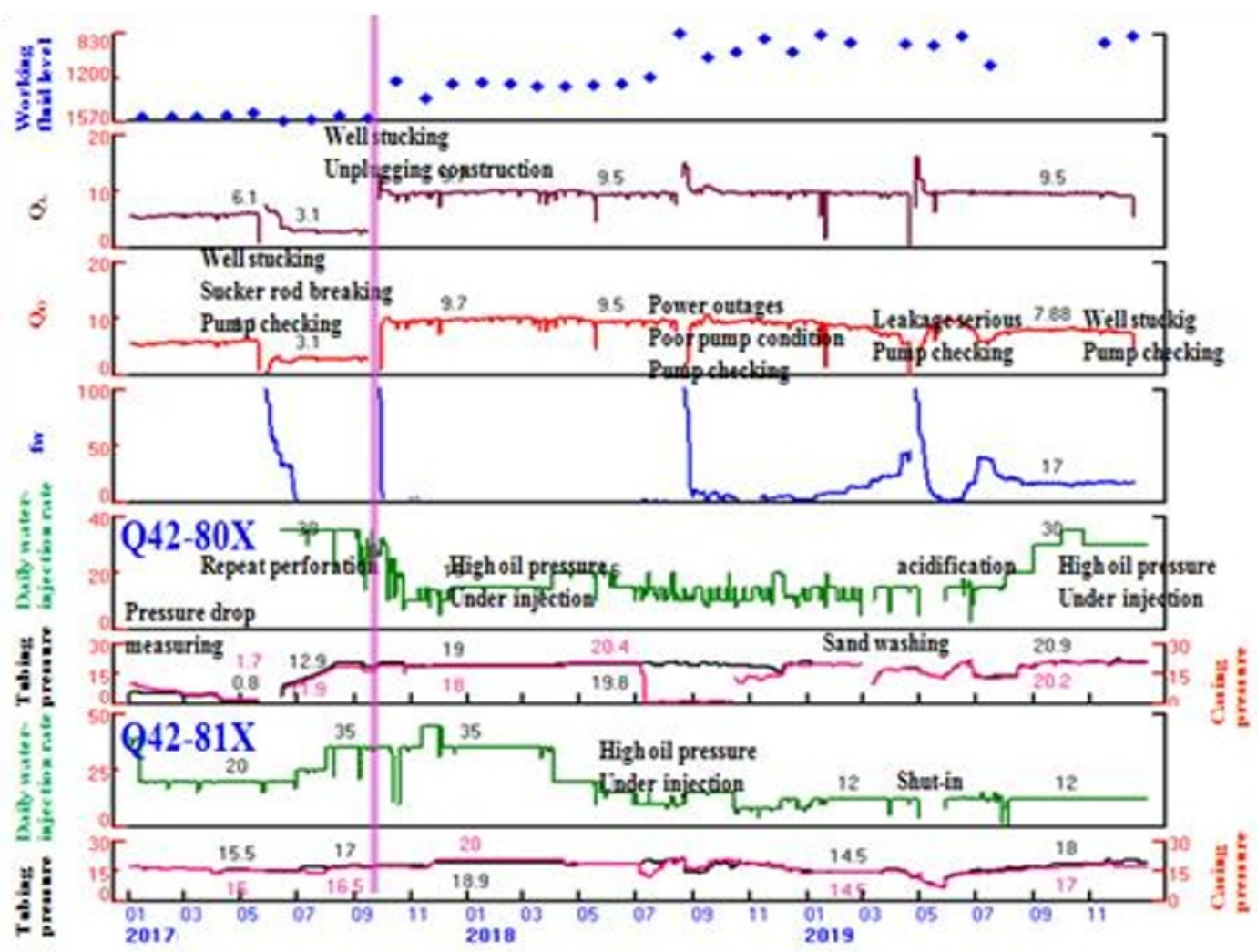

Figure 1 Production relationship curve of Q42-78X and Q42-80X \&Q42-80

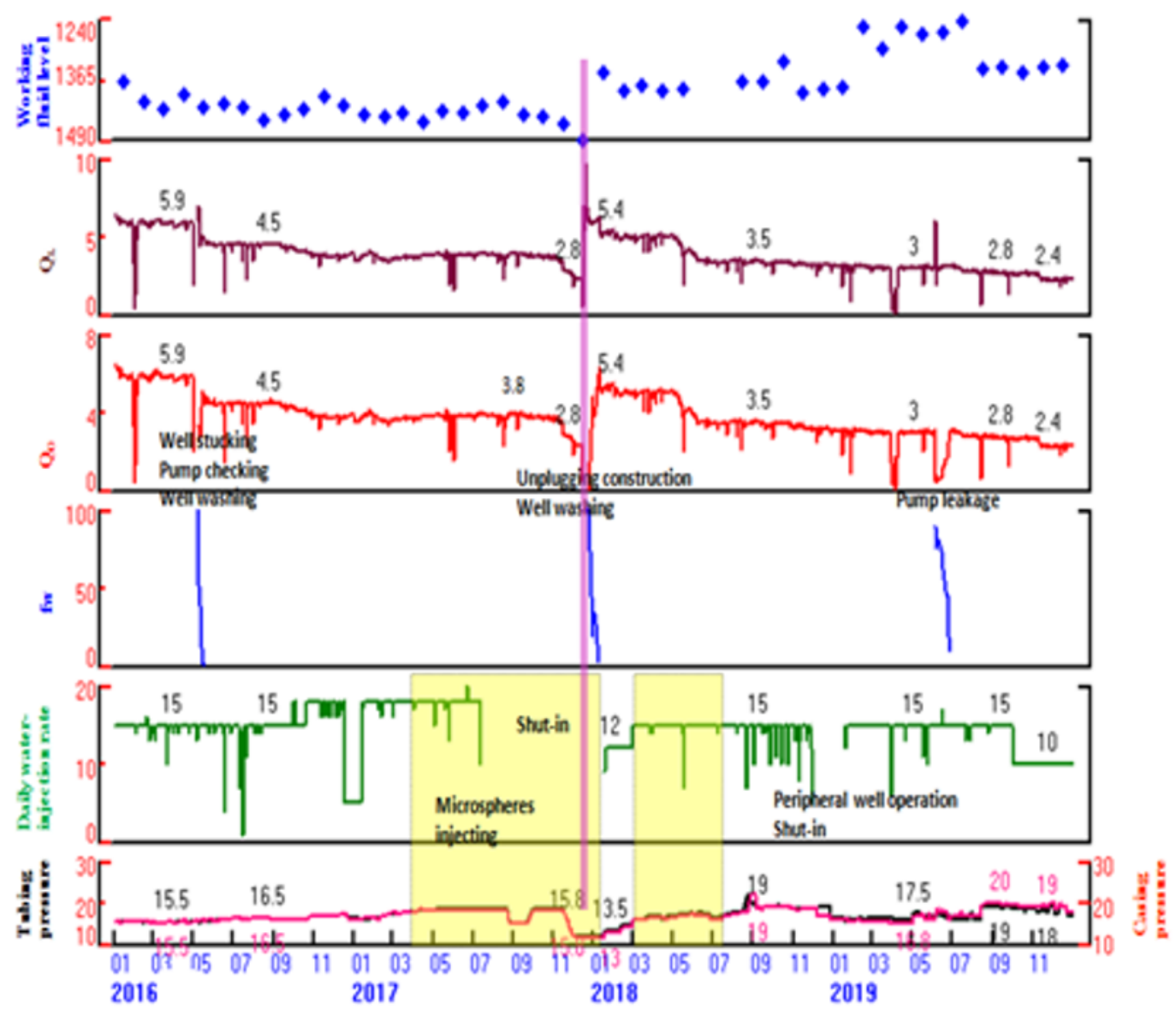

Figure 2 Production relationship curve of Q42-9X and Q42-17X 


\subsubsection{Analysis of blocking process and formula}

In order to further analyze the pertinence of unplugging technology, scale samples of rods and pipes on site were taken for analysis. And the cause of the formation clogging can be deduced from that. Table 2 is the statistical table of scale samples analysis results of some wells in 42 fault block. The results show that the scale samples of well Q42-72X and Q42-53 on sucker rod, tubing inner wall, sand settling pipe mortar and electric heating rod are mainly corrosion products and organic matter. From the scale sample analysis results of oil rod (pipe) site, it can be inferred that compound scale blockage composed of organic scale and inorganic scale is formed in the formation [6-11].
In addition, the key parameters of four unplugging wells in Q42 fault block were analyzed. It was reasonable that the unplugging agent dosage treatment radius was $0.75 \pm 0.15 \mathrm{~m}$. The basic formula of unplugging agent was organic acid $8 \%-10 \%$, anionic drainage aid $2 \%-2.5 \%$, small molecule anti-swelling gent $2 \%$ and imidazoline corrosion inhibitor $3 \%$, which was highly targeted to problems such as inorganic scale, organic scale, water locking, water sensitivity and pipe and rod corrosion. The treatment layer was $5.6-16.8 \mathrm{~m}$, but Q429X had a short validity period which had the thickest target layer. Therefore, for the wells with multi-layer production zones, it is suggested to remove blockage by layers in combination with the analysis of logging curve, production profile and remaining oil.

Table 2 Statistical table of scale sample analysis results of some wells in Q42 fault block

\begin{tabular}{|c|c|c|c|c|}
\hline location & Sucker rod & Inner wall of tubing & mortar in settling tube & electric heat pipe \\
\hline \multicolumn{5}{|l|}{ appearance } \\
\hline Oil content, $\%$ & 6.3 & 13.2 & I & 10.2 \\
\hline $\begin{array}{l}\text { Reduction at } 105^{\circ} \mathrm{C} \text { (light } \\
\text { hydrocarbons and water), } \%\end{array}$ & 1.1 & 0.9 & 1.4 & 1.2 \\
\hline Degeneration at $550^{\circ} \mathrm{C}$ (organic), $\%$ & 29.5 & 30.3 & 34.4 & 35.3 \\
\hline Deceleration at $950^{\circ} \mathrm{C}$ (carbonate), $\%$ & 3.5 & 2.2 & 2 & 6 \\
\hline acid non-soluble substance, $\%$ & 1.5 & 0.2 & 0.9 & 3.8 \\
\hline $\mathrm{Ca}^{2+}, \%$ & 4.9 & 3.6 & 2.6 & 10.6 \\
\hline $\mathrm{Mg}^{2+}, \%$ & 1.3 & 1.6 & 1.4 & 0.1 \\
\hline $\mathrm{Fe}^{3+}, \%$ & 10.4 & 8.7 & 7.9 & 4.8 \\
\hline $\mathrm{Fe}^{2+}, \%$ & 31.1 & 33.1 & 32.2 & 24.8 \\
\hline Conclusion & & osion products and or & & Organics and corrosion products \\
\hline
\end{tabular}

Table 3 Key construction parameters and process statistical analysis table for plug removing of fault block Q42

\begin{tabular}{|c|c|c|c|c|c|c|c|c|}
\hline No. & Well no. & $\begin{array}{c}\text { Daily oil increase } \\
\text { before and after } \\
\text { measure, } \mathbf{t} / \mathbf{d}\end{array}$ & $\begin{array}{c}\text { Unplug layer } \\
\text { thickness/layer } \\
\text { numbers, } \mathbf{m} / \text { layers }\end{array}$ & $\mathbf{T},{ }^{\mathbf{C}} \mathbf{C}$ & Unplugging agent formula & $\begin{array}{c}\text { Dosage of } \\
\text { unplugging } \\
\mathbf{3} \\
\text { agent, } \mathbf{m}\end{array}$ & $\begin{array}{c}\text { Dealing } \\
\text { radius, } \mathbf{m}\end{array}$ & $\begin{array}{c}\text { Construction } \\
\text { technology }\end{array}$ \\
\hline 1 & Q42-78X & 6.6 & $14.8 / 3$ & 60.6 & $\begin{array}{l}\text { Organic acid 10\%, anionic aid 2.5\%, small molecule anti- } \\
\text { swelling agent 2\%, imidazoline corrosion inhibitor 3\% }\end{array}$ & 20 & 0.66 \\
\hline 2 & Q42-74X & 1.18 & $12.2 / 4$ & 60.6 & $\begin{array}{l}\text { Organic acid 10\%, anionic aid 2.5\%, small molecule anti- } \\
\text { swelling agent 2\%, imidazoline corrosion inhibitor 3\% }\end{array}$ & 20 & 0.72 \\
\hline 3 & Q42-52X & 0.8 & $5.6 / 1$ & 52.8 & $\begin{array}{l}\text { Organic acid 8\%, anionic aid 2\%, small molecule anti- } \\
\text { swelling agent 2\%, imidazoline corrosion inhibitor 3\% }\end{array}$ & 15 & 0.92 \\
\hline
\end{tabular}




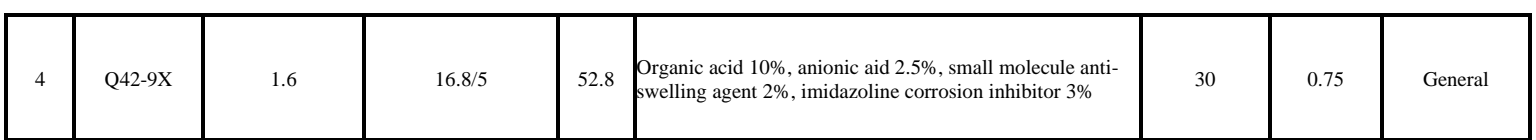

\subsection{Combine engineering with geology to further clarify the adaptability of existing technologies}

Based on the combination of reservoir and engineering, the application effect of chemical unplugging technology in the early stage is systematically analyzed. The adaptability of operation damage unplugging technology is further clarified. And the principle of well selection of this technology is standardized.

3.3 The number of wells used in the layered unplugging technology is less, so it is urgent to expand the application scale to clarify the applicability and effect of the technology

The layered unplugging process: the lower part of the jamming point $20-25 \#(11.4 \mathrm{~m} / 5$ layers $)$ should be unplugged first after the jamming is sealed. After the jamming is unsealed, the whole well section should be unplugged, whit a thickness of $33.6 \mathrm{~m} / 12$ layers.

\section{Conclusion}

This paper systematically analyzes the application of unplugging technology in typical block Q42. The application effect of the existing technology is systematically evaluated from the formulation of unplugging agent, unplugging process, damage mechanism, oil-water well relationship, production layer and other aspects. And the adaptability of this technology is obtained, and it is taken as the principle of well selection to further guide the application of technology and improve the application effect.

\section{Reference}

1. Zheng Yong, Cao Min, Wang Chaohua, etc. A novel retarded acidizing fluid and its uses for enhancement in water injectivity at Wennan oil field. Oilfield Chemistry, 2001, 18(3): 207 211.

2. Oil and gas industry standards: SY 5405-1996 《the method and evaluation index of performance of acid corrosion inhibitor》.

3. Zhao Fulin. Oil production chemistry. Shangdong Dongying: press. of petroleum university, 1989:15 18.

4. Fu Yarong. Understanding of oil well wax removal by hot washing[J].Jianhan oil production technology, 1997(1):13-14.

5. Fu Yarong. Plug removal technology of oil wells based on acid surfactants[J].Oil drilling \& production technology, 2007, 29(3):46-47.

6. Zhang Yan, Wang Zhengyong, Qu Renwei, etc. Formation damage and protection during the production of low permeability reservoirs in Kenli oilfield[J]. Journal of oil and gas technology, 2006, 28(2):100-102.
7. Ye Zhengrong, Fan Shizhong, Jiang Haijun. Indoors experimental research on formation temperature sensitivity in thermal production[J].Special oil \& gas reservoirs, 2000, 7(1):35-37.

8. Wang Fuhua, Qiu Zhengsong. Experimental study on the complicated formation damage prevention[J]. Petroleum drilling techniques, 2003, 31(5):42-45.

9. Zeng Daqian, Li Shuzhen. Types and characteristics of low permeability sandstone peservoirs in China[J]. ACTA PETROLEI SINICA.1994.15(1):38-41.

10. Chen Zhong, Zhang Shaonan, Shen Mingdao. Potential damages of clay minerals in oil-field protection[J]. Journal of Chendu University of Technology, 1996,23(2):80-86.

11. Shen Shouwen. Analysis of clay minerals and formation damage of Xiaermen oilfield reservoir[J]. Drilling fluid and completion fluid,1994, 11(3):5055. 